\title{
Tax Compliance, Income Distribution and Social Norms
}

\author{
Debora Di Gioacchino, Fabrizio Patriarca* \\ Sapienza University of Rome, Rome, Italy \\ Email: *fapatri@hotmail.com
}

How to cite this paper: Di Gioacchino, D. and Patriarca, F. (2017) Tax Compliance, Income Distribution and Social Norms. Theoretical Economics Letters, 7, 589-595. https://doi.org/10.4236/tel.2017.73044

Received: March 12, 2017

Accepted: April 21, 2017

Published: April 24, 2017

Copyright $\odot 2017$ by authors and Scientific Research Publishing Inc. This work is licensed under the Creative Commons Attribution International License (CC BY 4.0).

http://creativecommons.org/licenses/by/4.0/

\section{(c) (i) Open Access}

\begin{abstract}
This paper studies the effect of income inequality on tax evasion. To discuss the topic, we present a simple model, based on Benabouand Tirole [1], that incorporates incentives for tax compliance such as punishment and fines, intrinsic motivation and social norms. Since we consider a regressive system of incentives to comply, income inequality increases the value of tax evasion although overall propensity to comply is unaffected. In this framework, we consider the hypothesis that social norms are group specific as in the case of social segregation or status related networks. We show that all the negative effects of inequalities are amplified: the difference between the tax compliance of the income groups and the value of tax evasion increase.
\end{abstract}

\section{Keywords}

Tax Evasion, Social Norms, Income Distribution

\section{Introduction}

The relationship between income inequality and tax evasion is a complexone. Bloomquist [2] finds a positive correlation between a measure of income in equality (Gini coefficient) and the under reporting rate for wage and salary income.

On one hand, if individuals incentive for tax evasion is income related, then the share of tax evaders and the total amount of tax evaded depend on the distribution of income. On the other hand, the specific design ofthe tax system, together with social norms and laws, affect the after-tax distribution of income (see [3] for a discussion). Here we focus on the first issue: the effect of income inequality on taxevasion. The theoretical literature that has tried to explain the reasons for tax compliance has identified three motivations: extrinsic, intrinsic and reputational. In their seminal paper, Allingham and Sandmo [4] consider 
the decision on how much income an individual should report and how much should he evade as depending on his income, the fine to be paid in case of detection and the (subjective) probability of detection. They show that if the expected penalty is less than the tax rate then some tax evasion is optimal from the taxpayers point of view. Moreover, if in dividuals are risk-averse and absolute risk-aversion is decreasing, then richer in dividuals will evade more. Thus, in the standard models (see [4] [5]) evasion makes the tax system regressive. Along the lines of Gordon [6], several papers have incorporated tax morale into the standard models of tax evasion, recognising that people abstain from tax evasion not only for fear of being caught but also for moral and social considerations: agents have intrinsic motivation to behave prosocial andthey also like to appear i.e. have a reputation for being prosocial. Taxmorale is interpreted as a social norm for tax compliance and the strength of the norm is shaped endogenously, depending on the population share of honest citizens. If taxpayers care about socialstigma, the proportion of individuals who are expected to evadetax plays an important role in individual evasion decisions. The interdependence of individuals evasion decisions typically results in amultiplicity of equilibria. An economy with a given income distribution and tax system can either end up in a state with a strong socialnorm, where most taxpayers pay all their taxes, or a state witha weak social norm, where evasion is more wides pread. Kim [7] investigates the role of the income distribution on the existence of multiple equilibria, and, using numerical simulations, argues that multiple equilibria arise if taxpayer incomes are sufficiently homogeneous so that the social coordination effect dominates. Allowing for heterogeneity in individuals concern for social norms, Taxler [8] characterizes, analytically, the multiplicity of (social) equilibria in the share of evaders. He also considers tax compliance in a population consisting of subgroups with inter-group spill overs emphasizing the potential role of norm compliance in reference groups for taxmorale in other groups. Building on Benabou and Tirole [1], Besley et al. [9] use a simple model that includes intrinsic motivation, extrinsic incentives and social concerns to study the dynamics of taxevasion. They apply this framework to estimate the dynamics of tax evasion in the UK after the introduction of a poll tax in 1990.

In dealing with individuals incentive for tax compliance, our starting point is the model in [1] as applied to tax evasion in [9]. Their model includes in a simple way all the three motivations for tax compliancementioned above. To study the effect of inequality on tax evasion, we modify [9] by assuming two groups of agents differing in their income, but differently from them, we do not consider the dynamics of taxevasion.

In such a framework, income inequality can affect tax compliance through all its determinants: the intrinsic motivation, whenever its distribution among agents changes with income levels; the tax system, including the punishment and fines structure, as long as itis not proportional; and finally extrinsic motivations and social norm when they are determined according to income group specific features. In our case we do not consider the first motivation, thus the distri- 
bution of the intrinsic motivation is not correlated toincome. We will consider a tax system yielding a regressive system of incentives to tax compliance, including progressive taxation and nonproportional fines. Finally, we will us this setting to analyze the case in which social norms are group specific, which corresponds to the different cases of social segregation or network effects when networks have a social structure. We will show that income specificsocial norms increase the negative effect of inequalities on taxevasion, having a further regressive effect on disposable incomes. At the same time, the average social norms will not change since the higher number of payers between the agents on the bottom of the distribution will increase exactly as the number of richer agents evading.

\section{Baseline Framework}

We built up our analysis on the general model in [9]. There is a continuum of agents of unit mass maximizing:

$$
\max _{c} y-x(1-e)-(m+v) e+\mu E(v \mid e) ;
$$

where $y$ is income, $x$ the tax, $e \in(0 ; 1)$ the evasion decision (yes $=1 ; n o=0), m$ the expected economic cost of being caught, $v$ the subjective cost of evading having a density distribution $g(v), \mu$ the sensitivity to social norms, $E(v \mid e)$ the social norm effect given the choice $e$.

There is a cutoff value $v_{*}$ such that:

$$
m-x+v_{*}=\mu[E(v \mid e=1)-E(v \mid e=0)] .
$$

Given the density function of $v$ and its cumulate $G(v)$, tax will be evaded by $N$ $=G\left(v_{*}\right)$ agents for a total tax evasion of $T_{N}=x G\left(v_{*}\right)$.

If $v \sim U(0,2 \phi)$, then ${ }^{1}$ :

$$
E(v \mid e=1)-E(v \mid e=0)=v_{*}-\phi ;
$$

and thus using Equation (2):

$$
v_{*}=\frac{-\mu \phi+x-m}{1-\mu} .
$$

The share of tax evaders will be:

$$
N=\frac{v_{*}}{2 \phi}=\frac{-\mu \phi+x-m}{2 \phi(1-\mu)}
$$

for a total evasion $T_{N}$ equal to:

$$
T_{N}=x N=x \frac{-\mu \phi+x-m}{2 \phi(1-\mu)} .
$$

\section{Income Inequality and Regressive Incentives to Comply}

Having defined the benchmark model, we can now introduce the hypotheses of a constant fine systems and income inequality. We consider two types $i=(H ; L)$,

${ }^{1} E(v \mid e=1)-E(v \mid e=0)=E\left(v<v_{*}\right)-E\left(v>v_{*}\right)=\frac{v_{*}}{2}-\frac{2 \phi-v_{*}}{2}$. 
having income $y_{H} \geq y_{L}$ with $\alpha$ representing the share of agents of type $H$.

To use the previous section as benchmark we take:

$$
\bar{y}=\alpha y_{H}+(1-\alpha) y_{L}=y \text {. }
$$

If the distribution of $v$ is the same for each type, the number of evaders and the tax evaded will not change.

Let's consider instead the case of proportional tax $x_{i}=t y_{i}$ and aconstant $m$. All the following results same propositions hold when $m=m_{0}+m_{1} y_{i}$ as long as $m_{1}<t$ once we substitute $t$ with $t-m_{1}$ and $m$ with $m_{0}$. In the same way, they hold when taxation is not progressive using the opposite transformation. The maximization problem becomes:

$$
\max _{c} y_{i}-x_{i}(1-e)-(m+v) e+\mu E(v \mid e)
$$

For each type, there is a cutoff value $v_{*}^{i}$ such that:

$$
m-t y_{i}+v_{*}^{i}=\mu[E(v \mid e=1)-E(v \mid e=0)]
$$

where:

$$
\begin{aligned}
E(v \mid e=1)-E(v \mid e=0)= & (1-\alpha) E\left(v<v_{*}^{L}\right)+\alpha E\left(v<v_{*}^{H}\right) \\
& -(1-\alpha) E\left(v>v_{*}^{L}\right)+\alpha E\left(v>v_{*}^{H}\right)
\end{aligned} .
$$

If $v \sim U(0,2 \phi)$, then we will have the equivalent ${ }^{2}$ of Equation (3):

$$
E(v \mid e=1)-E(v \mid e=0)=\bar{v}_{*}-\phi ;
$$

where:

$$
\bar{v}_{*}=(1-\alpha) v_{*}^{L}+\alpha v_{*}^{H}
$$

using $9^{3}$ :

$$
v_{*}^{H}-v_{*}^{L}=t\left(y_{H}-y_{L}\right) ;
$$

then $^{4}$ :

$$
\begin{gathered}
v_{*}^{L}=\bar{\nu}_{*}-\alpha t\left(y_{H}-y_{L}\right) \\
v_{*}^{H}=\bar{\nu}_{*}+(1-\alpha) t\left(y_{H}-y_{L}\right) .
\end{gathered}
$$

Furthermore we have:

$$
\bar{\nu}_{*}=\frac{-\mu \phi+t \bar{y}-m}{1-\mu}=v_{*} ;
$$

and thus:

$$
\begin{aligned}
& (1-\alpha) E\left(v<v_{*}^{L}\right)+\alpha E\left(v<v_{*}^{H}\right) \\
& -(1-\alpha) E\left(\left(v>v_{*}^{L}\right)-\alpha E\left(v>v_{*}^{H}\right)\right. \\
& =(1-\alpha) \frac{v_{*}^{L}}{2}+\alpha \frac{v_{*}^{H}}{2}-(1-\alpha) \frac{2 \phi-v_{*}}{2}-\alpha \frac{2 \phi-v_{*}^{H}}{2} \\
& =(1-\alpha) v_{*}^{L} \alpha+v_{*}^{L}-\phi \\
& { }^{3} \text { Indeed we have: } m-t y_{i}+v_{*}^{i}=\mu\left(\bar{v}_{*}-\phi\right) i=H, L . \\
& { }^{4} m-t y_{L}+v_{*}^{L}=\mu\left[v_{*}^{L}-\phi-\alpha\left(v_{*}^{H}-v_{*}^{L}\right)\right]=\mu\left[v_{*}^{L}-\phi-\alpha t\left(y_{H}-y_{L}\right)\right] ; \\
& v_{*}^{L}=\frac{-\mu \phi+t y_{L}-m+\alpha \mu t\left(y_{H}-y_{L}\right)}{1-\mu} .
\end{aligned}
$$




$$
\bar{N}=\alpha \frac{v_{*}^{H}}{2}+(1-\alpha) \frac{v_{*}^{L}}{2}=\frac{\bar{v}}{2}=N .
$$

Finally ${ }^{5}$

$$
\bar{T}=T_{N}+t^{2} \frac{\alpha(1-\alpha)}{2}\left(y_{H}-y_{L}\right)^{2}
$$

As expected, the type $H$ evade more than the type $L$, the two thresholds $V_{*}^{H}$ and $V_{*}^{L}$ are respectively increasing and decreasing in inequality (Equation (15), Equation refdue), and the value of evasion is increasing in inequality (Equation (18)). However, the number of evaders and the average social norms vare unaffected by inequality (Equation (16)): the increase in inequality brings about an increase of tax payers of group $L$ equal to the increase in evaders of group $H$.

\section{Group Specific Social Norms}

If the two types are not in contact we will have ${ }^{6}$ :

$$
\begin{gathered}
\hat{v}_{*}^{L}=\bar{v}-t \frac{\alpha\left(y_{H}-y_{L}\right)}{1-\mu}>v_{*}^{L} \\
\hat{v}_{*}^{H}=\bar{v}+t \frac{(1-\alpha)\left(y_{H}-y_{L}\right)}{1-\mu}>v_{*}^{H} \\
\hat{v}_{*}=\bar{v}
\end{gathered}
$$

Evasion in group $L$ is lower and evasion in group $H$ is higher. Thus, the differences between the social norms of the two groups widen.

Coherently with Equation (21) we have:

$$
\hat{N}=\alpha \frac{-\mu \phi+t y_{H}-m}{2(1-\mu)}+(1-\alpha) \frac{-\mu \phi+t y_{L}-m}{2(1-\mu)}=N
$$

Average tax compliance and the number of evaders doesn't change.

Finally ${ }^{7}$ :

$$
\hat{T}_{N}=T_{N}+t^{2} \frac{\alpha(1-\alpha)}{2(1-\mu)}\left(y_{H}-y_{L}\right)^{2}>\bar{T} .
$$

The value of evasion increases.

Taking together all these results we can conclude that when socialnorms are group specific and economic incentives to comply are regressive, the effects of

${ }^{5} T_{N}=\alpha t \frac{v_{*}^{H}}{2} y_{H}+(1-\alpha) t \frac{v_{*}^{L}}{2} y_{L}=\alpha t \frac{\bar{v}_{*}+(1-\alpha)\left(v_{*}^{H}-v_{*}^{L}\right)}{2} y_{H}+(1-\alpha) t \frac{\bar{v}_{*}-\alpha\left(v_{*}^{H}-v_{*}^{L}\right)}{2} y_{L} ;$

using Equation (13):

$T_{N}=\alpha t \frac{\bar{v}_{*}+(1-\alpha) t\left(y_{H}-y_{L}\right)}{2} y_{H}+(1-\alpha) t \frac{\bar{\nu}_{*}-\alpha t\left(y_{H}-y_{L}\right)}{2} y_{L}=t \frac{\bar{v}}{2} \bar{y}+t^{2} \frac{\alpha(1-\alpha)}{2}\left(y_{H}-y_{L}\right)^{2} ;$

using eq.6 we obtain Equation (18).

$$
\begin{aligned}
{ }^{6} \hat{v}_{*}^{i} & =\frac{-\mu \phi+t y_{i}-m}{(1-\mu)}=\bar{v}+t \frac{y_{i}-\bar{y}}{1-\mu} . \\
\hat{T}_{N} & =t y_{H} \alpha \frac{-\mu \phi+t y_{H}-m}{2(1-\mu)}+t y_{L}(1-\alpha) \frac{-\mu \phi+t y_{L}-m}{2(1-\mu)}=T_{N}+t y_{H} \alpha \frac{t\left(y_{H}-\bar{y}\right)}{2(1-\mu)}+t y_{L}(1-\alpha) \frac{t\left(y_{L}-\bar{y}\right)}{2(1-\mu)} . \\
& =T_{N}+t^{2} \frac{\alpha(1-\alpha)\left(y_{H}-y_{L}\right) y_{H}+\alpha(1-\alpha)\left(y_{H}-y_{L}\right) y_{L}}{2(1-\mu)}
\end{aligned}
$$


inequalities are amplified and there is a final further regressive effect since, as in the case of higher inequality, segregation increase the number of tax payers of group $L$ to the same extent of the increase in evaders of group one.

\section{Conclusions}

In this article, we have introduced a framework to assess the role of income inequalities in a standard model of tax compliance with social norms. We have considered economic incentives to comply decreasing in income as a consequence of progressive taxation or regressive fines. Thus, higher income inequality increases the value of evasion while overall social norms are unaffected since the increase of evaders inthe richer class is equal to the decrease of tax payers in the lower income class. The regressive nature of the incentives to comply also determines a further regressive effect on the distribution of disposable income.

Once introduced the benchmark framework, we have considered the hypothesis that social norms are formed separately by income groups as in the case of social segregation or network effects when networks have a social structure. Group specific social norms amplify all the negative effects of inequalities: the difference between the tax compliance of the two groups and the value of tax evasion increase while overall social norms are constant.

This model provides a benchmark for the analysis of tax compliance when agents are heterogeneous and social norm are group specific. Policies aimed at increasing compliance can rely on the social norm effects, instead of higher controls or higher fines and punishments. From these perspective, since the disclosure of information about evaders is not always an option, analternative channel is to reduce segregation effects in the process of formation of social norms.

\section{Acknowledgements}

We thank for the support: "Progetto di Ricercad'Ateneo 2105-Sapienza University of Rome".

\section{References}

[1] Tirole, J. and Bnabou, R. (2011) Laws and Norms. NBER Working Paper, No. 17579 .

[2] Bloomquist, K.M. (2003) Income Tax Evasion: A Theoretical Analysis. OECD Papers, 3, 1-27.

[3] Lee, K. (2016) Norms and Monetary Fines as Deterrents, Anddistributive Effects. Journal of Economics, 190, 1-27.

[4] Sandmo, A. and Allingham, M.G. (1972) Income Tax Evasion: Atheoretical Analysis. Journal of Public Economics, 104, 323-338.

[5] Yitzhaki, S. (1974) A Note on Income Tax Evasion: A Theoretical Analysis. Journal of Public Economics, 3, 201-202.

[6] Gordon, J.P.F. (1989) Individual Morality and Reputation Costs as Deterrents to Tax Evasion. European Economic Review, 33, 797-805.

[7] Kim, Y. (2003) Income Distribution and Equilibrium Multiplicity in a Stigma-Based Model of Tax Evasion. Journal of Public Economics, 87, 1591-1616. 
[8] Traxler, C. (2017) Social Norms and Conditional Cooperative Taxpayers. European Journal of Political Economy, 26, 89-103.

[9] Persson, T., Besley, T. and Jensen, A. (2015) Norms, Enforcement and Taxevasion. CEPR Discussion Paper, 104, 323-338.

Submit or recommend next manuscript to SCIRP and we will provide best service for you:

Accepting pre-submission inquiries through Email, Facebook, LinkedIn, Twitter, etc. A wide selection of journals (inclusive of 9 subjects, more than 200 journals) Providing 24-hour high-quality service User-friendly online submission system Fair and swift peer-review system Efficient typesetting and proofreading procedure Display of the result of downloads and visits, as well as the number of cited articles Maximum dissemination of your research work

Submit your manuscript at: http://papersubmission.scirp.org/ Or contact tel@scirp.org 